\title{
A TRANSFORMAÇÃO PROMOVIDA PELA ECONOMIA CRIATIVA NA SOCIEDADE INFORMACIONAL: UMA DISCUSSÃO TENDO EM VISTA A GLOBALIZAÇÃO E O ESTADO NACIONAL
}

Nathalie de Paula Carvalho

Mestre em Direito Constitucional pela Universidade de Fortaleza. Doutoranda em Direito pela Universidade Federal de Santa Catarina.

Filomeno Moraes

Professor titular do Programa de Pós-Graduação em Direito Constitucional/Mestrado e Doutorado da Universidade de Fortaleza (UNIFOR).

\section{Resumo}

A pretensão desta pesquisa analisa os contornos de um fenômeno que se desenvolve recentemente: uma proposta econômica criativa, um processo ainda em construçáo e com contornos ainda obscuros, tendo em vista os avanços tecnológicos e a situação do indivíduo na sociedade informacional. Neste contexto, este artigo tem por objetivo investigar o surgimento da economia criativa - um conceito ainda em construçáo - na denominada sociedade da informaçáo, com o objetivo de verificar o comportamento dos agentes econômicos no cenário do neoliberalismo, principalmente enfocando a análise no aspecto cultural, aliando os contextos constitucional e econômico em um mesmo instituto: a economia cultural. Com uma tessitura crítica, buscar-se-á compor um catálogo de medidas de proteçâo da cidadania ativa contra o sufocamento ditado pelos detentores da informação, bem como seus modos de transmissão. Pretende-se, afinal, demonstrar esta relação mútua e necessária nos dias atuais.

\section{Palavras-chave}

Economia Criativa; Cultura; Desenvolvimento.

\section{Resumen}

La intención de esta investigación analiza los contornos de un fenómeno recientemente desarrollado: una propuesta económica creativa, un proceso aún en construcción y 
con contornos poco claros, dados los avances tecnológicos y la situación del individuo en la sociedad informacional. En este contexto, el artículo tiene como objetivo investigar la aparición de la economía creativa - un concepto en construcción - en la llamada sociedad de la información, con el fin de verificar el comportamiento de los agentes económicos en el escenario neoliberal, centrándose principalmente en el análisis en el aspecto cultural, la combinación de los contextos constitucionales y económicas en el mismo instituto: la economía cultural. Con un tejido crítico, se buscará componer un catálogo de medidas de protección de la ciudadanía activa contra la sofocación dictada por propietarios de la información, así como sus formas de transmisión. El objetivo es poner fin a este espectáculo el respeto mutuo y necesario hoy en día.

\section{Palabras clave}

Economía Creativa; Cultura; Desarrollo.

\section{Introdução}

A economia atual capitaneia um processo que não se sabe como ou quando irá terminar. Antes de teorizar acerca dessa afirmação, é necessário um mínimo desvio, que visualize o porquê do leitor dos dias presentes ter compreendido o efeito dessa sentença inicial. De uma maneira ou de outra, qualquer indivíduo se insere num processo econômico quando compra, vende, troca, empresta, aluga, doa, recebe, enfim, quando realiza qualquer ato negocial.

A propósito disso, os processos econômicos do mundo contemporâneo não se restringem a limites territoriais e, portanto, qualquer indivíduo de hoje é um ator econômico integrado à economia de todo o planeta. Assim, a repercussão de uma prática, por mais simples que pareça, já não se exaure num encadeamento de eventos simples.

A realidade contemporânea implica no reconhecimento de que a revoluçáo tecnológica (RIFKIN, 2012) é a orientadora das mais diversas searas: humanas, econômicas, socais, estruturais, etc. Trata-se de um sistema de comunicação que é trazido em uma língua universal digital, moldurando a vida ou sendo por ela moldada por meio, por exemplo, de redes interativas de computadores.

Essas mudanças confusas e descontroladas levam as pessoas a se reagruparem em torno de identidades primárias, ou seja, as religiosas, as étnicas, as territoriais ou simplesmente nacionais. A riqueza, o poder e a imagem, nesse contexto, estão materializados em um mundo de fluxos na busca de uma identidade coletiva ou individual com uma fonte de significação pessoal. 


\section{Uma Sociedade Informacional}

Com o paradigma da integração promovida pela globalização assentado, a economia compreendeu que a participaçáo de um ator econômico, por menor monta que tivesse, representaria uma propulsão geral das riquezas circulantes ou, em termos vulgares, o bolo econômico cresceria à medida que todos os nichos negociais se aglutinassem. E então, como num holograma, um ponto isolado passou a náo representar quase nada, mas a união das suas extremidades é condição essencial à formação do todo.

Com a adoção espontânea das práticas neoliberais ou com a imposição delas, por intermédio das economias centrais do capitalismo, todas as estruturas econômicas do mundo se imbricaram de uma tal forma, a não existir mais empresas de um país apenas ou bolsas de valores de uma comunidade econômica restrita e, enfim, cidadãos que não sofram o influxo da macroeconomia mundial em seu cotidiano. A economia atual, ladeada pela tecnologia indomável, globalizando determinados comportamentos, estandardizando soluçóes econômicas e imprimindo até mesmo conceitos culturais, teria iniciado algo irreversível.

A par do contexto que há pouco se introduziu, é necessário frisar que o sistema capitalista, por quaisquer das formas que já assumiu ao longo da história, foi e é marcado por duelos, que tanto podem ser examinados isoladamente, quanto podem ser analisados uns a partir dos outros, transparecendo, assim, seu caráter de nascedouro infinito de contradiçôes e, ao mesmo tempo, de solucionador incansável dessas mesmas contradiçóes.

De logo, o conflito que mais interessa a esta análise é entre o capitalismo e a democracia. Isto é, o quanto a livre atuação econômica invade a seara política, tanto dos representantes eleitos como, de resto, de todos os cidadãos. Deve-se supor quanto o capitalismo, propositalmente, cadencia a educação e a participação política de todos os cidadãos.

Os indivíduos são responsáveis pela tomada de decisôes estratégicas em redes de intercâmbios instrumentais responsáveis pela conexão ou desconexão de pessoas, grupos ou países. É uma sociedade estruturada entre a rede e o ser (CASTELLS, 2007), materializada por vezes em uma "esquizofrenia" estrutural.

A ausência de comunicação promove uma alienação entre os grupos sociais e indivíduos, na medida em que o "outro" seria considerado uma ameaça. Trata-se da "geração internet" (TAPSCOTT, 2010). Com isso, a fragmentação social se propaga por meio de uma racionalidade, uma ação social significativa e uma política transformadora, tudo orientado pela tecnologia, o atual contexto social:

Este novo conceito de informação gerador de conhecimento não surgiu por acaso. É fruto de uma nova sociedade, tecnologicamente complexa e cuja velocidade no trânsito de dados e, por conseguinte, as necessidades urgentes do novo superam a cada minuto décadas inteiras outrora 
experimentadas pela humanidade. Esta nova sociedade que conduziu a um novo conceito de informação também fez surgir novas formas de controle, armazenamento e distribuição desta informação. A informação é uma palavra que enseja uma complexidade que a torna de difícil definição no contexto da Revolução da tecnologia da informação. Isto porque, para fazer uso da informação, faz-se necessário que ela exista que seja conhecida e que se encontre disponível (WACHOWICZ, 2006, p. 40).

Vale mencionar, entretanto, que a tecnologia não determina a sociedade, haja vista que uma somatória de fatores como a criatividade, a iniciativa empreendedora, a descoberta científica e a inovação tecnológica devem ser levadas em consideração nesta complexa análise.

A interação com o mundo, neste formato, representa um novo estilo de produção, comunicação, gerenciamento e vida social (GUARREIRO, 2006). A formação de redes é o resultado imediato desta interação. Pela lente econômica, pode-se afirmar que as inovações tecnológicas são objeto de apropriação pelos países, na medida em que considera a tecnologia, a sociedade e as transformações históricas como orientadores deste processo, realidade vela pela intervenção estatal, uma fundamental força nesse âmbito (v.g. China, Japão e a extinta URSS).

Importante salientar a diferença entre os modos de desenvolvimento - o industrialismo e o informacionalismo - e os modos de produção - capitalismo e socialismo (ou estatismo). O chamado pós-industrialismo é o palco da tecnologia da informação. Poderia ser considerada uma reestruturação do sistema capitalista? Análises mais direcionadas para a era da informação apontam para uma resposta afirmativa.

Surge uma nova ordem estrutural social, ordenada pelo modo de desenvolvimento do informacionalismo. As relaçóes sociais - produção (relaçóes entre as classes), experiência (históricas, familiares) e poder (institucionalização da representatividade estatal) ganham robustez no que se relaciona com a complexa rede de comunicaçóes que conecta o mundo.

Formam-se as culturas e as identidades coletivas, por meio de uma comunicação por vezes simbólica entre os seres humanos, promovendo o relacionamento destes com a natureza e, principalmente, com o fator tecnologia. Alia-se o conhecimento à informaçáo.

Tem-se um princípio de desempenho estruturante, calcado no industrialismo - crescimento da economia e maximização da produção - e o informacionalismo - desenvolvimento tecnológico, acumulação de conhecimentos, níveis de complexidade do processamento da informação. Seria uma "perestroyka capitalista” para Manuel Castells (2007).

Não se deve olvidar o palco em que desfila a sociedade da informação: uma economia de mercado. O Neoliberalismo consiste em um conjunto de ideias políticas e econômicas 
capitalistas que defende a mínima participação estatal nos rumos da economia de um país: "para manter os lucros, o capital precisa estar constantemente explorando novos mercados" (HELD, McGREW, 2001, p.16).

Prega-se a minimização do Estado, tornando-o mais eficiente pela abertura da economia para o capital internacional e a sua desburocratização. Contraria-se a tributação excessiva, a favor do aumento da produção, como objetivo básico de atingir o desenvolvimento econômico.

Os críticos mais atentos ao sistema afirmam que a economia neoliberal só beneficia as grandes potências econômicas e as empresas multinacionais. Os países pobres ou em processo de desenvolvimento sofrem com os resultados de uma política neoliberal, marcados por consequências devastadoras dessa ideologia: desemprego, baixos salários, aumento das diferenças sociais, monopólios, dependência do capital internacional, afastando-se de possíveis soluçóes para esses problemas, v.g. uma melhor distribuição de renda para diminuir a pobreza, melhorias na educação, a responsabilidade do capital e do trabalho, diretrizes para o bem-estar social, etc.

Ao seguir a orientação neoliberal, a globalização pode ser concebida como um fenômeno que possui tanto um lado positivo (desenvolvimento geral das populaçóes) como negativo (males sociais, políticos, econômicos, exclusão social) ${ }^{1}$. Enquanto as distâncias físicas e virtuais encolhem, aumenta-se a velocidade da interação social, de modo que os acontecimentos mundiais possuem uma reverberação quase imediata a nível global. Fabio Wanderley Reis destaca os malefícios, ao apontar que:

Essa estrutura [globalizada] revela mesmo traços que podem ser descritos como próprios de uma sociedade de castas, em que se superpóem mundos sociais radicalmente distintos, separados por profundo fosso quanto a condiçóes de vida e unidos somente por formas de intercâmbio antes precárias e restritas a determinadas esferas de atividade. A dinâmica tecnológica e econômica que se afirma como parte das tendências novas da globalizaçáo náo autorizam qualquer otimismo no que se refere à sua eventual contribuição para melhorar esse quadro de desigualdade. Ao contrário, o que temos com ela, mesmo nos países economicamente mais avançados, são o aumento da desigualdade social, níveis inéditos de desemprego, a 'nova pobreza', o aumento da violência urbana (REIS, 1997, p. 49).

A globalização é um processo não pede licença. Nem precisaria. Por conta disso, será mais dispendioso para alguns, mas, com o tempo, as vantagens surgirão para a maioria.

1 Cf. SILVA JÚNIOR, Ary Ramos. Globalização, Estado Nacional e Democracia: as transformaçōes do capitalismo e seus impactos econômicos, sociais, políticos e espaciais. Economia \& Pesquisa. Araçatuba, n. 6, mar. 2004, p. 25. 
Lembra também que se trata de um dado da realidade, de modo a exigir uma visão estratégica que preveja os custos e benefícios dos seus resultados.

Pela ótica da Psicanálise social (BARGLOW, 2013), a tecnologia está ajudando a desfazer uma visão de mundo por ela desprovida no passado, por conta desta nova conectividade promovida em uma identidade partilhada, reconstruída. Quando a rede desliga o ser - individual ou coletivo - é erguido um significado sem a identificação instrumental global. Nesse contexto, a desconexão promove a exclusão social.

A necessidade da dinâmica do capitalismo de formar uma "aldeia global" 2 que permita maiores mercados para os países centrais impulsiona a globalização, no que diz respeito à forma como ocorre uma maior interação e aproximação entre as naçóes, interligando o mundo e, para isso, levam-se em consideração os aspectos econômicos, sociais, culturais e políticos ${ }^{3}$.

Trata-se de uma realidade em que é possível a realização de transaçóes financeiras, a expansão de negócios até então restritos a pequenos mercados de atuação para outros mais distantes e emergentes, sem necessariamente um investimento alto de capital financeiro, proporcionado pela eficiente comunicação do mundo globalizado.

George Ritzer (2007, p. 01-33) define a globalização como a difusão das práticas capitalistas, expansão de relações através de continentes, organização da vida social em uma escala global e crescimento de uma consciência mundial compartilhada, a que chama "sociedade civil global".

Em outras palavras, a globalização é um fenômeno que se apresenta como um processo de internacionalizaçáo das práticas capitalistas, uma interligação de mercados nacionais e internacionais com a diminuição das barreiras alfandegárias e liberdade expressiva para o fluxo de capital no mundo.

Não há uma dissociação radical entre o "global" - representado pelas multinacionais, pelo terrorismo internacional, pela indústria do entretenimento, pela rede mundial de computadores - e o "local" - marcado pela noção de cidade, de etnicidade, de fontes tradicionais de identidade. Para corroborar seu raciocínio, enfatiza que a globalização pode ser apontada como uma das razóes do ressurgimento de identidades culturais locais em várias partes do mundo.

O movimento de internacionalização do capital é excludente, por natureza. Está em curso um nítido movimento tendente à conexão dos países desenvolvidos e em desenvolvimento, haja vista que o discurso ideológico da globalização, o qual procura mostrar que

2 Cf. IANNI, Otávio. Era do globalismo. Rio de Janeiro: Civ. Brasileira, 1996, p. 50.

3 Cf. HÖFFE, Otfried. Visão republicana mundial: democracia na era da globalizaçáo. Revista Trimestral de Filosofia da PUCRS (Veritas). Porto Alegre, v. 47, n. 04, dez., 2002, p. 555. 
a abertura econômica é uma das possíveis soluçóes para a crise econômica - atualmente em grande evidência - vem conseguindo cumprir seus objetivos, acentuando cada vez mais as ligaçôes socioeconômicas.

\section{A Economia Criativa}

Antes de adentrar no complexo tratamento da economia criativa, cumpre apresentar alguns conceitos fundamentais para a compreensão da temática. Inicialmente, demonstra-se a diferença entre um bem - relacionado com a ideia de circulação, agregando-se, portanto, um valor econômico adequado ao respectivo mercado - e uma obra - conectada diretamente com a criação, valores estéticos e culturais.

Reputa-se salutar um retorno a década de 40, quando surgem as primeiras consideraçóes sobre a denominada Indústria da Cultura, alvo de severas críticas pela Escola de Frankfurt, mais precisamente por Theodor Adorno (2002). Está intimamente relacionada com a cultura das massas, com um cunho ideológico preponderante no que diz respeito aos novos métodos de industrialização na esfera cultural.

Nesse contexto, surge a criatividade como a mola propulsora da Terceira Revolução Industrial, nas palavras de Jeremy Rifkin (2012). Este é o ponto de partida da economia criativa, ou seja, seu principal insumo: a criatividade. $\mathrm{O}$ patrimônio cultural apresenta-se como um complexo de bens culturais valorados. O mercado seria a "palavra-chave" para a inserção desta categoria jurídica no cenário social e econômico, gozando de proteção legal pela importância e repercussóes que surgem desta relação entre a coisa criada e o seu criador. Para Celso Furtado:

Evidentemente, [a criatividade] não se trata de um ato lúdico, e sim de uma ação que visa satisfazer uma necessidade humana, mesmo que esta seja tão somente virtual, ainda que não concretizada pelos contemporâneos. Neste caso, o ato criativo amplia as possibilidades do ser humano, enriquece-lhe a vida. As necessidades humanas se apresentam em ordens diversas e tendem a uma crescente complexidade (FURTADO, 2012, p. 91-92).

Cumpre ressaltar que a criatividade, entendida como a movimentação do intelecto humano com objetivo de criar algo novo, remonta desde a Idade da Pedra Lascada (ou Período Paleolítico da História Antiga), até mesmo como um fator de sobrevivência para os seres daquela época. Naturalmente, náo havia que se falar em resguardo jurídico nesta época (MATTELART, 2002).

Na sociedade contemporânea, porém, a criatividade é tratada como um fator de produção: "o ato criativo se manifesta na produção de obras excepcionais, que enriquecem o patrimônio da humanidade, como obras que se incorporam imediatamente ao viver cotidiano de certas comunidades" (FURTADO, 2012, p. 95). 
E é neste ponto que a economia criativa surge propondo e reverberando a necessidade do surgimento de novos modelos de produção, crucial para a manutenção do próprio sistema de mercado. A circulação de informação, recorde-se, é a base da sociedade informacional. Trata-se de um conceito ainda em construção, variando as definiçóes de acordo com o contexto em que o termo é proposto.

Em linhas gerais, a economia criativa representa os setores criativos, que agregam novos valores inerentes a sociedade da informação. Esses novos modelos de relaçóes requerem uma proteção jurídica que legitime esta conexão e, principalmente, exista para limitar e condicionar as condutas humanas nesse sentido. Fala-se ainda em uma Economia da Cultura (TOLILA, 2007).

A análise da economia criativa se apresenta em um meio sistêmico, na medida em que a sociedade está inserida em um ambiente multifacetário. Pode-se afirmar que, sob o aspecto da denominada sustentabilidade integral e/ou sistêmica, o mundo representa um ecossistema socioambiental, não se traduzindo apenas como um ambiente tangível, aquele natural e tecnológico, mas também o ambiente intangível, protagonizado pela sociedade e pela sua cultura.

O capitalismo, em suma, representa uma síntese entre uma recompensa do trabalho, uma recompensa da poupança, o risco inerente a atividade qualificada como econômica, ladeada por um espírito minimamente empreendedor, a inventividade e a criatividade, essencial na denominada economia criativa.

Isso se reflete em todo tipo de processo e estrutura, que terá sempre uma parte tangível - o suporte estrutural - e uma parte intangível - a inteligência, o processo que origina a função criativa. Essa divisão acadêmica aponta para 4 (quatro) vetores de percepção, devendo-se: (i) identificar desequilíbrios; (ii) otimizar resultados; (iii) identificar oportunidades (iv) aproveitar as tecnologias de modo eficiente.

O principal objetivo desta modificação sistêmica seria a inclusão social e dos setores que estão fora do mercado, sendo a economia criativa um modelo de negócios, além de um compartilhamento e, por via de consequência, um desenvolvimento sustentável. Assim, por meio de uma visão reducionista, os bens intelectuais seriam considerados commodities primárias, mas a mudança de estratégias do desenvolvimento convencionais promove o surgimento de novos agentes. Esta análise, conforme restou demonstrada, deve ser interdisciplinar (Economia, Antropologia, Direito, Cultura).

Pergunta-se: como? O Ministério da Cultura (on line, 2011, p.127) aponta alguns exemplos de políticas públicas destinadas a promover e a regulamentar algumas manifestaçôes de economia criativa, a saber: (i) maior oferta e concentração de mão de obra qualificada com geração e difusão de conhecimentos tácitos, (ii) maior fluxo de consumidores e consolidação de mercados, (iii) fortalecimento da economia local no setor de 
serviços, (iv) maior ganho de infraestrutura e interesse do poder público em proporcionar melhor infraestrutura e segurança, (v) maior produção e difusão de informaçôes, de conhecimento e de bens intelectuais; e, (vi) endogeinização de habilidades com utilização plena da capacidade produtiva para suprir demandas minimizando a necessidade de agentes externos. A partir destas diretrizes, o Estado pode, ao lado do setor empresarial, unir forças e determinar um incremento em uma atividade econômica, acrescida dos adjetivos “sustentável” e "criativa”.

A proteção desta espécie de direitos, principalmente os denominados direitos autorais, pressupóe uma diversidade cultural, quesito considerado direito fundamental pela Constituição Federal de 1988. A inserção e a incorporação das tecnologias como fatores de produção têm por função estimular a inclusão social. A constituição econômica brasileira (MORAES, 2011) também se encontra como pilar destes aspectos intrinsecamente relacionados com a eclosão da economia criativa, pautando-a e orientando-a com seus princípios expostos no art. 170.

Este aquecimento social e econômico, temperados com a força da sociedade da informação, torna possível o surgimento de novos bens culturais. O avanço é veloz. A economia criativa representa categorias dos setores criativos, com uma volátil estrutura de mercado cultural. Apresentam-se, naturalmente, as justificativas e consequências das políticas culturais, na medida em que o cenário da economia da cultura renova as consideraçóes sobre o real valor para a sociedade, presentes nas mais diversas formas de vida.

Vale ainda mencionar o impulso que a promoção da cultura fornece para uma determinada sociedade em formato de empregos, geração de renda para os entes federativos que explorem a cultura de forma setorial, com a cobrança de preços muitas vezes módicos e, com esta movimentação, a oferta de subsídios. Essa (re) orientação demonstra a diferença entre o consumidor racional - ligado à economia padrão - e o consumidor cultural, na medida em que, nesta seara, a propriedade seria usufruída coletivamente.

Ainda há de se observar o caráter da remuneração variável nos chamados "empregos culturais", o que poderia ser considerado um desestímulo para a imersão neste tipo de mercado (BENHAMOU, 2007). Os museus, por exemplo, possuem como fontes de financiamento o Estado, o mecenato e as receitas próprias, ao mesmo tempo em que convive com as dificuldades inerentes a administração e os custos elevados com as aquisiçóes, exposiçóes e manutençóes necessárias. As obras de arte, vale dizer, possuem um valor de mercado, agregado ao prazer da contemplação, admiração, coleção (PAESANI, 2007).

Nesta toada, pode-se afirmar que o direito autoral encontra guarida na lógica da escassez da sociedade industrial, mas não se encaixa abundancia e velocidade da economia criativa. Não se deve olvidar que a titularidade destes bens é a coletividade. Essas indústrias culturais, pela sua dinamicidade, promovem a implantação de politicas públicas, por 
meio também da diversidade cultural, um terreno fértil para a criatividade. Celso Furtado salienta que:

Numa sociedade democrática, já não basta tornar mais intensa a acumulação. É igualmente importante garantir a abertura de espaços para a participaçáo de todos. Se é verdade que o crescimento econômico pode se fazer, em geral, pela importação de modelos estrangeiros, o desenvolvimento cultural, em contrapartida, implica sempre na percepçáo da identidade de um povo, sem o que ele jamais terá autonomia indispensável à criação (FURTADO, 2012, p. 187).

Paul Tolila (2007) argumenta que é fundamental esta relação entre a cultura e a economia, haja vista que existem cinco fases em que essa ligação pode ser percebida na produção de um bem cultural: a criação, a edição/produção, a fabricação, a distribuição e a comercializaçáo pública. (TOLILA, 2007, p. 38-39). Ao lado disso, percebe-se uma ampliação do setor cultural pelo turismo, pelo valor espiritual que a cultura desperta. Assim, a economia se transforma como a emblemática "economia do conhecimento" (TOLILA, 2007, p. 92), onde a interpretação dos símbolos se mostra determinante.

A ideia inicial é unir os processos de a criação, planejamento, produção, distribuição e divulgação de produtos e serviços tendo como base de origem o capital intelectual, a criatividade, nível de conhecimento e recursos materiais disponibilizados, além de modelos de gestão e de negócios. Veja-se:

Em suma, a economia criativa é composta por áreas da economia que tem como base a inventabilidade individual de criar produtos e serviços que tenham impacto positivo na sociedade de consumo e gerem renda e lucros para a empresa ou para o empreendedor. A economia das ideias tem sido um dos principais caminhos para a manutenção de mercados de países desenvolvidos e em desenvolvimento. Além dos pontos e setores econômicos tradicionais como diminuição dos custos com a mão-de-obra, investimentos em maquinaria para viabilizar uma produção mais rápida de produtos e avanço tecnológico, o campo das ideias tem superado esses setores, sendo a criatividade uma das dianteiras dessas ações (REBOUÇAS, on line, 2013).

Nesta oportunidade, apresenta-se uma crítica a auto regulação da economia, na medida em que se vive em uma sociedade complexa. Seria uma superação ou uma adaptação do livre mercado? A resposta é indefinida. O que se pode afirmar é o surgimento de uma nova proposta metodológica de uma análise econômica da cultura (TOLILA, 2007, p. 124), sem a pretensão de fornecer respostas exatas a um conceito ainda em construção. $\mathrm{O}$ método se traduz no fornecimento de incentivos, estímulos para o conhecimento, sempre velando por uma padronização teórica (TOLILA, 2007, p. 115). 
A Convenção da Diversidade Cultural, lançada em 2005 pela UNESCO, afirma que as politicas e medidas culturais são traduzidas nos seguintes termos: criação, produçáo, difusão, distribuição das atividades em forma de bens ou serviços e, principalmente, o acesso.

\section{Conclusões}

O ser na sociedade informacional possui uma identidade, que se manifesta em instrumentalidades e comunicação via comunidades virtuais. Assim, o atributo mencionado apresenta o indivíduo como um ator social e constrói seu significado por um atributo cultural, referências calcadas em estruturas sociais. Todo esse processo de (re) construção recebe o incremento indispensável da globalização.

Constata-se que todos os antagonismos de interesses correspondem, na verdade, aos anseios das pessoas em sua condição de investidoras, de consumidoras e, no lado oposto da guerra hermenêutica, os almejos dessas mesmas pessoas, em sua condição de cidadãs. É compreensível que a problematização da democracia é algo muito mais complexo que o simples atendimento do impulso de consumir, já culturalmente condicionado, por isso, tấo fácil a irresponsabilidade nos investimentos, na transmissão de informação (v.g. lei $12.527 / 11$ ) e no consumo e tâo enleadas as atitudes democráticas mais razoáveis (PAESANI, 2007).

Todavia, em algum momento histórico a cultura precisa recondicionar seus indivíduos a encontrar o equacionamento da questão, sob pena de, qual a esfinge mitológica, a questão devorar a todos. Com todo o exposto, urge que as questôes do dia-a-dia, que raramente são conectadas a esses raciocínios macropolíticos e macroeconômicos, pela maioria da população, sejam, finalmente, entendidas, por esse mesmo público.

A globalização traz em si a força de uma nova reordenação das relaçóes mundiais. Nesse contexto, unilateralmente imposto, o discurso democrático não tem um porta-voz que o represente, tornando-se obsoleto, pois a sua proposta de diminuir as desigualdades sociais e econômicas não conseguem se impor, deficiências estas que tornam o ideal democrático inoperante.

Neste cenário, acrescente-se que "o princípio da função social não teve vida fácil. Defrontou a hostilidade do liberalismo e individualismo a que se opunha; mas foi também combatido pelo coletivismo ascendente, para o qual representava uma estratégia para obstar à supressão pura e simples da propriedade" (ASCENSÃO, 2006, p. 89).

Os seus próprios discursos, carregados pelas suas próprias contradições, apresentamse sem capacidade para entender e justificar as novas manifestaçóes da exclusão social que acontecem mundialmente, impedindo-os de apresentar soluções realmente viáveis. 
A mídia, nesse processo, deve ser transformada, também. A responsabilidade e a ética na informação são fundamentais. Como na "sociedade de massas", a opinião pública tornou-se o editorial do grande jornal, faz-se imprescindível que o grande jornal canalize, honestamente, o anseio cidadão.

A economia criativa surge no cenário econômico hodierno como um instrumento a favor do desenvolvimento econômico com um ingrediente diferenciado, haja vista que utiliza como principal insumo a criatividade e o talento, individual ou coletivo. Foge dos interesses meramente especulativos comuns às atividades econômicas tradicionais, pois também integra socialmente. Deste modo, trata-se de uma meta de adequação aos anseios sociais já tão olvidados pelo Poder Público. É uma oportunidade.

Assim, as origens econômicas, castigadas pelos solavancos da história com inúmeras crises e superaçôes, abre as portas para uma nova forma de enxergar a economia e fornecer um aparato técnico e instrumental para o implemento desta forma de exploraçáo características tão peculiares aos seres humanos: a capacidade de criar.

Ao lado disso, as mudanças de orientaçóes pautadas pelos clamores relacionados com o Direito Ambiental na busca de um desenvolvimento sustentável, representam o cenário ideal para a proliferação destes empreendimentos de cunho inovador. A ala empresarial acompanha esta tendência e busca retirar destas práticas o que lhes convêm. Natural que assim seja, haja vista que o oportunismo caminha lado a lado com a busca por diferentes e eficientes alocaçóes de esforços que resultem em recursos, de preferência em formato de lucro. A tentativa é aliar estas duas orientaçôes.

\section{Referências}

ADORNO, Theodor. Indústria cultural e sociedade. Trad. Augustin Werner e Jorge Mattos Brito de Almeida. 5. ed. São Paulo: Paz e Terra, 2002.

ASCENSĀO, José de Oliveira. A função social do direito autoral e as limitaçóes legais. In: ADOLFO, Luiz Gonzaga Silva; WACHOWICZ, Marcos (Org.). Direito de propriedade intelectual: estudos em homenagem ao Pe. Bruno Jorge Hammes. Curitiba: Juruá, 2006. p. 85-112.

BARGLOW, Raymond. The crisis of the self in the age of information: computers, delphins, and dreams. Disponível em: < http://catalogo.biblioteca.iscte-iul.pt/cgi-bin/ koha/opac-search.pl?q=su:Psican\%C3\%A1lise>. Acesso em: 5 abr. 2013.

BENHAMOU, Françoise. A economia da cultura. São Paulo: Ateliê, 2007.

CASTELLS, Manuel. A era da informação: a sociedade em rede. São Paulo: Paz e Terra, 2007. 
FURTADO, Celso. Ensaios sobre cultura e o Ministério da Cultura. São Paulo: Contraponto, 2012.

GUARREIRO, Evandro Prestes. Cidade Digital: infoinclusão social e tecnologia em rede. São Paulo: Senac, 2006.

HELD, David. McGREW, Anthony. Prós e contras da globalização. Trad. Vera Ribeiro. Rio de Janeiro: Jorge Zahar, 2001.

HÖFFE, Otfried. Visão republicana mundial: democracia na era da globalização. Revista Trimestral de Filosofia da PUCRS (Veritas), Porto Alegre, v. 47, n. 4, dez. 2002.

IANNI, Otávio. Era do globalismo. Rio de Janeiro: Civilização Brasileira, 1996.

MATTELART, Armand. História da sociedade da informaçáo. 2. ed. São Paulo: Loyola, 2002.

MINISTÉRIO DA CULTURA. Plano da Secretaria da Economia Criativa: políticas, diretrizes e açôes, 2011-2014. Brasília: Ministério da Cultura, 2011.

MORAES, Filomeno. A constituição econômica brasileira: história e política. Curitiba -PR: Juruá Editora, 2011.

PAESANI, Liliana Minardi. O direito na sociedade da informaçáo. São Paulo: Atlas, 2007.

REBOUÇAS, Fernando. Economia criativa. Disponível em: <http://www.economiacriativa.com/ec/pt/ec/index.asp>. Acesso em: 25 nov. 2013.

REIS, Fábio Wanderley. O nacional e o social em tempos globais. In: GERSCHMAN, Sílvia. VIANNA, Maria Lúcia Werneck (Org.). A miragem da pós-modernidade: democracia e políticas sociais no contexto da globalização. Rio de Janeiro: Fiocruz, 1997. p. 43-51.

RIFKIN, Jeremy. A terceira revolução industrial. São Paulo: M. Books, 2012.

RITZER, George. Globalization: a new conceptualization. In: The Globalization of nothing. California: Pine Forge Press, 2007. p.1-33.

SILVA JÚNIOR, Ary Ramos. Globalização, Estado Nacional e Democracia: as transformaçôes do capitalismo e seus impactos econômicos, sociais, políticos e espaciais. Economia \& Pesquisa. Araçatuba, n. 6, p.11-25, mar. 2004.

TOLILA, Paul. Cultura e economia. São Paulo: Iluminuras, 2007.

TAPSCOTT, Don. A hora da geraçáo digital: como os jovens que cresceram usando a internet estão mudando tudo, das empresas aos governos. Trad. Marcello Lino. Rio de Janeiro: Agir Negócios, 2010. 
WACHOWICZ, Marcos. A revolução tecnológica da informação: os valores éticos para uma efetiva tutela jurídica dos bens intelectuais. In: ADOLFO, Luiz Gonzaga Silva; WACHOWICZ, Marcos (Org.). Direito de propriedade intelectual: estudos em homenagem ao Pe. Bruno Jorge Hammes. Curitiba: Juruá, 2006. p. 39-84. 